\title{
CUERPO Y LITERATURA: UNA INTRODUCCIÓN. LA FENOMENOLOGÍA EXISTENCIAL DE MAURICE MERLEAU-PONTY Y LA MEMORIA COLECTIVA DE MAURICE HALBWACHS
}

\author{
RUBÉN DARÍO BARRETO VIANA ${ }^{1}$ \\ Universidad del Atlántico. Km 7 Antigua Vía a Puerto Colombia. \\ Puerto Colombia, Colombia. \\ dariov.cienfuegos@hotmail.com
}

\section{RESUMEN}

El estudio de la memoria colectiva en la tesis de grado titulada Tiempo artístico y Memoria Colectiva: La Casa Grande y Álvaro Cepeda Samudio, derivó en la postulación de una serie de conclusiones acerca del papel que cumple la obra literaria en la disposición de los recuerdos compartidos. Por lo tanto, la finalidad de esta investigación es la depuración del modelo de análisis de la memoria colectiva a partir de la integración de la corporalidad al conjunto de variables construido por Maurice Halbwachs en La Memoria Colectiva (2004). Para esto se recurre a la fenomenología existencial de Maurice Merleau-Ponty, que proporciona un esquema teórico-metodológico que permite subdividir en tres categorías a los diferentes aspectos que envuelven al cuerpo: 1. Percepción 2. Movimiento 3. Instrumentalidad, los cuales contribuyen al desmonte crítico de En la colonia penitenciaria de Frank Kafka (1995) y Bartleby, el escribiente de Herman Melville (2010).

Palabras Clave: Memoria Colectiva, Literatura, Corporalidad, Fenomenología Existencial, Merleau-Ponty, Sociología del Cuerpo.

\footnotetext{
${ }^{1}$ Sociólogo. Universidad del Atlántico.
} 
BODY AND LITERATURE: AN INTRODUCTION. THE EXISTENTIAL PHENOMENOLOGY OF MAURICE MERLEAU-PONTY AND COLLECTIVE MEMORY OF MAURICE HALBWACHS

\section{ABSTRACT:}

The study of collective memory in the work of degree titled Tiempo artístico y Memoria Colectiva: La Casa Grande y Álvaro Cepeda Samudio, derived in the postulation a set of conclusions about the role that fulfill the literary work in disposition of shared memory. Therefore, the finality of this investigation is the depuration of the collective memory analysis model through the integration of the corporeality at the set of variables structured by Maurice Halbwachs in La Memoria Colectiva (2004). For this it makes use the existential phenomenology of Maurice Merleau-Ponty, that provides a theoretical-methodological scheme that enable to subdivide in three categories the aspects differents of the human body: 1 . Perception 2. Movement. 3. Instrumentality, that contribute to the critic disassemble of En la colonia penitenciaria by Frank Kafka (1995) y Bartleby, el escribiente by Herman Melville (2010).

Key Words: Collective Memory, Literature, Corporeality, Existential Phenomenology, Merleau-Ponty, Sociology of Body.

\section{Introducción}

El planteamiento crítico de un proyecto investigativo basado en la relación existente entre literatura y memoria colectiva implica la transversalización de los métodos de observación aplicados a uno y otro objeto de estudio. Ello con el finque estos puedan complementarse al momento de realizar el diagnóstico de una obra literaria en tanto proyección simbólica de los recuerdos compartidos sobre un hecho social determinado. De esta forma, en líneas generales, la reconstrucción del acervo de representaciones e imaginarios propios de la memoria colectiva que se conservan en una obra literaria solo puede llevarse a cabo a través de la deconstrucción del enfrentamiento ideológico y valorativo que subyace en el entramado de relaciones discursivas que establecen los personajes a lo largo de la trama narrativa. 
A la luz de lo anterior, dos preguntas se apoderan de nuestra inquietud: ¿Realmente es posible una investigación que cumpla a cabalidad con estos requerimientos? Y si es así ¿Qué tipo de resultados arroja? Para responder a estos interrogantes tenemos que remitirnos al trabajo de investigación titulado Tiempo artístico y Memoria Colectiva: La Casa Grande y Álvaro Cepeda Samudio (Barreto, Tesis de grado inédita, 2015), que propone asumir la trama narrativa de La Casa Grande como una Red Conceptual de Acción (Ricoeur, 2004, p. 129), es decir, como una estructura de sentido conformada por un número variable de agentes (individuales o colectivos) que orientan sus acciones (algo que alguien hace) de acuerdo a ciertos motivos (por qué alguien hace algo) y hacia el cumplimiento de determinados fines (compromiso de aquél de quien depende la acción). En este sentido, cabe añadir que dichos agentes siempre se enfrentan a limitaciones normativas, producto de circunstancias históricas concretas, que favorecen o dificultan el curso de la acción, lo que da lugar a la instauración de relaciones de cooperación/lucha/competencia entre los diferentes agentes que coexisten en el sistema en aras de asegurar el éxito y evitar la frustración de sus propósitos.

Ahora, la circulación de la información no es del todo clara en el texto, por lo que es necesario un análisis formal de sus componentes. En este caso particular se utilizó el modelo triádico de Genette (1989), el cual nos proporcionó una integración congruente de los hechos de la trama. Una vez que se obtiene la línea de desarrollo lógico-temporal de las acciones y acontecimientos vividos en el relato, se procede a la organización del contenido significativo del texto ${ }^{2}$ sobre la Masacre de las Bananeras ocurrida en 1928. Esto debido a que permite situar la posición de los recuerdos de los personajes (como miembros y portadores de la visión de mundo de un grupo humano específico) al interior de cada uno de los marcos sociales de la memoria (Memoria Individual, Historia, Tiempo y Espacio) descritos por Maurice Halbwachs (2004). En efecto, a partir de estos índices

\footnotetext{
${ }^{2}$ Las categorías a considerar son: Íncipit (Duchet, 1971), Visión de mundo (Goldmann, 1975), Cronotopo (Bajtín, 1989), Ideosema (Cros, 1992), Ideologema (Cros, 2003).
} 
operativos se logró fijar las siguientes conclusiones que presentamos a continuación:

a. La identificación de tres Visiones de mundo plenamente diferenciadas: Visión de mundo del grupo Patricio conservador, que se identifica con una concepción patriarcal y feudal-colonial de la sociedad; Visión de mundo Oficial del Gobierno, que tiene una concepción centralista del Estado, y que basa su dominio sociopolítico en el monopolio del uso legítimo de la fuerza física; Visión de mundo del Pueblo (Jornaleros/Mujeres/Líderes sindicales).

b. La construcción ideológica del espacio-tiempo en la figura del Cronotopo, es decir, la estructura formal de la novela se corresponde o se ajusta a las relaciones y prácticas sociales de un grupo social determinado. De esta manera, La Casa Grande se vale de dos cronotopos principales: El Cronotopo Idílico, que se basa en un tiempo-espacio rígido y cíclico, en el que los patrones de comportamiento se mantienen invariables a través del sostenimiento de la dialéctica de Mando/Obediencia y la transmisión del Odio como valor generacional; son defensores de este cronotopo la Visión de mundo del grupo Patricio conservador y la Visión de mundo Oficial del Gobierno. El Cronotopo del Umbral, que abre una fase de transición crítica con la irrupción de lo extranjero, pone en entredicho la validez del Cronotopo Idílico, porque deriva en una problematización de sus modos de proceder (valores sociales) y en una apertura de los canales dialógicos para la instauración de un nuevo sistema-mundo; son partidarios de este cronotopo la Visión de mundo del Pueblo, el primer soldado, la Hermana, el Hermano y los Hijos.

c. Los hechos cruciales que son mediatizados por la Memoria Colectiva pueden extraerse de la obra literaria a partir de la observación de los Ideosemas ${ }^{3}$, que

\footnotetext{
${ }^{3}$ Instrumento para el análisis de las representaciones que estructuran y establecen el entramado significativo del texto. Con este concepto se pretende un acercamiento a dicho proceso de estructuración, ya que su origen siempre apunta a una práctica social proveniente del nivel pretextual o el afuera del texto. Con lo anterior, el Ideosema es simultáneamente, un articulador semiótico y discursivo, debido a que el texto logra absorber aquellos sistemas de signos icónicos, gestuales o lingüísticos socializados externos a su dominio para darle consistencia y coherencia a su propia estructura discursiva. (Cros, 1992, p. 203).
} 
polarizan los diferentes discursos sociales alrededor de un tema, un acontecimiento, o un personaje específico. En La Casa Grande se encuentran dos series ideosémicas que se retroalimentan: la primera tiene que ver con el surgimiento y la represión de la huelga (La Huelga/El Desembarco de los soldados/La Masacre), mientras que la segunda se inscribe en la lucha ideológica entre los habitantes de la casa grande (La Infancia/El Odio/El Embarazo de la Hermana/El Juicio/El Matrimonio concertado/La Muerte del Padre).

d. La experiencia de los personajes es unánime en torno a la alteración del tiempo social pues, a pesar de que cada visión de mundo tiene un modo distintivo de emplearlo en sus relaciones y prácticas colectivas, la demarcación que existe entre los intervalos en que este se divide está supeditada al servicio de trenes, el cual ha sido interrumpido por la Huelga y la Masacre.

e. La respuesta de las visiones de mundo a la alteración del tiempo social es espacial. Esto se debe a que el rasgo principal del espacio es la estabilidad, es decir, el mantenimiento de la disposición de los objetos materiales ofrece un soporte a la disolución del esquema temporal. De hecho, cada visión de mundo cuenta con un lugar de pertenencia, así la visión de mundo Patricio conservadora se refugia en la casa grande, la visión de mundo oficial del Gobierno se aloja en el cuartel, y la visión de mundo del pueblo reparte su vida social entre las casas de techo de láminas de zinc y la plantación.

f. La Constelación de Ideologemas ${ }^{4}$ es un fenómeno discursivo caracterizado por la conformación de una imagen significativa, es decir, la instauración de representaciones e imaginarios sociales. En este sentido, la Constelación de Ideologemas sobre la Huelga en el capítulo El Decreto se empeña en catalogar las acciones de los huelguistas dentro de un perfil criminal y violento, así como la Constelación de Ideologemas del capítulo Sábado se basa en un discurso jurídico

\footnotetext{
4 "Microsistema semiótico-ideológico subyacente en una unidad funcional y significativa del discurso. Esta se impone en un momento dado en el Discurso social con una recurrencia excepcionalmente alta. El microsistema que se va instituyendo de esta forma se organiza en torno a unas dominantes semánticas y a una serie de valores que fluctúan según las circunstancias históricas" (Cros, 2003, p. 250).
} 
amparado en el Código Penal de 1890 para acreditar, en ambos casos, la intervención del ejército en la zona bananera.

g. La Polémica Oculta es un fenómeno discursivo de rivalización ideológica, pues se rebate constantemente la posición del interlocutor con la finalidad de cuestionar la información que algunos personajes nos proponen acerca de los hechos y sus protagonistas. De esta manera, la Polémica Oculta entre el primer y el segundo soldado implica una relevancia especial en la medida que nos presenta como un hecho (La Huelga) puede construirse socialmente de acuerdo a la visión de mundo que lo mediatiza en el discurso.

h. El odio, valor de transmisión generacional, tiene un doble carácter (Ideosema e Ideologema) debido a que puede dirigir el curso de la discusión y encarnar el sistema ideológico/valorativo de la estructura social patriarcal.

i. La interacción entre el tiempo social y la historia nos permite descubrir la unidad básica para enmarcar los recuerdos individuales en el flujo de la Memoria Colectiva: La Fecha. En efecto, a partir del registro del día en que se encuentra fechado el decreto firmado por el General Cortés Vargas, fue posible datar los principales acontecimientos del antes, durante y después de la Masacre de las Bananeras. Como instancia adicional, la historia también contribuye a la construcción de la Memoria Colectiva gracias a que es capaz de cristalizar la visión de mundo de grupos sociales que se han dispersado; tal es el caso de la visión de mundo oficial del Gobierno, que expresa su posición a través de documentos militares: El Decreto (El Decreto) y El informe/bitácora/crónica (Sábado).

j. El cuerpo como sujeto de significación en los siguientes escenarios: Los Ideologemas cuerpo, olor, llanto, entidad, entre otros, que expresan las circunstancias emocionales que padecen los personajes bajo el influjo de ciertas condiciones temporales o espaciales. La Somatización de la Incertidumbre, manifestación discursiva de las secuelas corporales que ocasionan las constricciones que ejerce una visión de mundo sobre un personaje. 
No obstante, si bien los Ideologemas y la Somatización de la Incertidumbre se encuentran catalogados desde una perspectiva nominal en cuanto tipificación de sus principales componentes, estos fenómenos no pueden encuadrarse satisfactoriamente dentro de las categorías conocidas de la memoria colectiva. Ello debido a que no existe una adecuación de las experiencias sensitivas de los personajes y de sus medios de expresión frente a un parámetro de ponderación que estime la incidencia del cuerpo en las relaciones y prácticas de los grupos sociales. Esto quiere decir que la evidente incompleción de los alcances conceptuales de la memoria colectiva ${ }^{5}$ constituye en sí misma una oportunidad para la introducción de nuevos elementos de análisis sociológico/literario, puesto que los diferentes estados o procesos que se suscitan en el cuerpo, a pesar de tener un origen biológico, también cuentan con un soporte social que dispone los modos en que estos deben o pueden usarse para proyectar las estructuras significativas que rigen las dinámicas de intercambio colectivo.

Por lo tanto, la finalidad de este artículo no está dirigida específicamente a la reseña de Tiempo artístico y Memoria Colectiva: La Casa Grande y Álvaro Cepeda Samudio, sino a la revisión y ampliación del material de estudio que constituye dicho trabajo investigativo, de tal manera que pueda perfeccionarse el modelo teórico-metodológico empleado para el análisis sociológico de la memoria colectiva en la literatura. Con lo anterior, es necesario desenfocar por un momento nuestra atención de las configuraciones que adquiere la memoria colectiva en este caso particular y desplazar el eje de la discusión hacia la problemática de la corporalidad, ya que la definición de esta variable proporcionará los instrumentos básicos para la aprehensión de los recursos simbólicos referidos al cuerpo que la memoria colectiva deposita en las obras literarias.

\footnotetext{
${ }^{5}$ Más que una crítica, se busca la continuación y unificación de los esfuerzos alrededor de la obra de Maurice Halbwachs, que dejó inconclusa su categorización de la Memoria Colectiva. Recordemos que el anexo de la versión póstuma de La Memoria Colectiva está dedicado a la Memoria Colectiva en los músicos (Halbwachs, 2004, pp. 163-190).
} 


\section{Hacia una definición teórico-metodológica del Cuerpo}

Entonces ¿Qué es el cuerpo? La dilucidación de este enunciado supone una secuenciación argumentativa que parta desde una definición de las propiedades que distinguen al cuerpo hasta la enumeración rigurosa de los métodos de observación y tratamiento de cada una de estas propiedades. Para realizar esta tarea se utilizará un sustrato filosófico-sociológico que dé cuenta de las principales transformaciones conceptuales de esta variable y la asimilación de sus características inherentes.

En consonancia con lo previo, la tradición fenomenológica de MerleauPonty (1993) inicia la explicitación de la corporalidad a partir de la noción de êtreau-monde $^{6}$ (ser-del-mundo), que consiste en la manifestación plena de la existencia del sujeto a través de su experiencia vital del medio en el que se halla inmerso. En otras palabras, la forma primordial que permite tanto la apropiación sensible de los objetos como el reconocimiento de sí mismo y de los otros en un contexto dado. En este sentido, el cuerpo basa su relación con el mundo en dos características puntuales: 1. La Percepción 2. El Movimiento.

En cuanto a la percepción, Merleau-Ponty señala que esta es la unidad básica que comunica la presencia del mundo en el que nos desenvolvemos, porque el cuerpo se encarga de mediatizar las relaciones que se establecen con los objetos que componen el horizonte de la vida y de la acción. Esto quiere decir que, bajo este presupuesto, no existe una escisión entre sujeto y objeto, sino que el cuerpo se convierte en la inserción efectiva de la consciencia en el mundo vivido. De este modo, el cuerpo ocupa un lugar privilegiado entre los objetos exteriores en la medida que su permanencia (continuo estar-ahí), en contraposición a la contingencia con que aparecen otros objetos, dota al sujeto de una coordenadas espacio-temporales que le hacen posible organizar y poseer una

\footnotetext{
6 "La expresión original «être au monde», que traducimos por "ser-del-mundo», evoca en francés, como el lector vera en la descripción que de la misma da el autor, pertenencia ontológica al mundo a la par que existencia en el: "ser en el mundo», «estar en el mundo», "ser del mundo». Ha parecido que la formula «ser-del-mundo», aunque un tanto rígida, era la más aproximada al sentido de la concepción original subyacente en la locución «être au monde», y preferible a la formula literaria «estar abocado a» (N. del T.)". (Merleau-Ponty, 1993, p. 97).
} 
perspectiva (dominio perceptivo) con la que se aproxima al mundo y de la que extrae el sentido de las cosas (Merleau-Ponty, 1993, pp. 108-110).

De hecho, y aquí ingresamos al terreno del movimiento, la predisposición del cuerpo a habitar en una perspectiva respecto al mundo vivido deviene en una toma de consciencia total de sus procesos motrices, y con ello, el consabido control de su espacialidad (Merleau-Ponty, 1993, p. 116). Así, las partes del cuerpo no deben ser entendidas como un conjunto acoplado por una adición mecánica de bloques separados, pero sí como una unidad que coincide de manera íntegra e indiferenciada. De esta manera, la puesta fenoménica del cuerpo en un todo envuelto por ciertos contornos se traduce en un esquema corpóreo, denominación que aborda la facultad que tiene el cuerpo para convertirse en una función dinámica que tiende a o se orienta al cumplimiento de una meta real o factible:

$\mathrm{Si}$, de pie delante de mi mesa, me apoyo en ella con mis dos manos, solamente estas quedarán acentuadas y todo mi cuerpo seguirá tras ellas como una cola de cometa. No es que yo ignore la ubicación de mis hombros o de mis lomos, lo que ocurre es que esta queda envuelta en la de mis manos y toda mi postura se lee, por así decir, en el apoyo que estas toman sobre la mesa. Si, estando de pie, tengo mi pipa en mi mano cerrada, la posición de mi mano no viene determinada discursivamente por el ángulo que esta forma con mi antebrazo, mi antebrazo con mi brazo, mi brazo con mi tronco, mi tronco con el suelo. Sé dónde está mi pipa con un saber absoluto, y por ende sé dónde está mi mano y donde mi cuerpo (...). (Merleau-Ponty, 1993, p. 117)

Es por ello que la espacialidad de los objetos difiere de la espacialidad del cuerpo, porque, mientras aquella se ciñe a una posición que sirve de referencia para ubicar otros objetos, esta se corresponde con la intuición inmediata que tiene el cuerpo de su situación (actualidad espacio-temporal), incluso en la derivación constante de sus movimientos; por tanto, el cuerpo se hace dueño del aquí, es decir, el asidero a partir del cual se ramifican sus decisiones. Sin embargo, es imprescindible el entrecruzamiento del espacio objetivo y el espacio corpóreo, ya que esto posibilita la estructuración de un espacio inteligible, escenario en el cual el cuerpo ordena sus acciones (se mueve) para hacer manipulables los objetos que tiene a su alcance: 
(...) si mi cuerpo puede ser una 〈〈orma〉y si puede haber delante de él unas figuras privilegiadas sobre unos fondos indiferentes, es en cuanto que esta polarizado por sus tareas, que existe hacia ellas, que se recoge en sí mismo para alcanzar su objetivo, y el «esquema corpóreo» es finalmente una manera de expresar que mi cuerpo es-del-mundo. (Merleau-Ponty, 1993, pp. 117-118)

En últimas, el cuerpo es un acto potencial, pues ya sabe o conoce por anticipado el plano en el que puede o no ejecutar su potestad, pero, antes de continuar, es preciso agregar que el movimiento corporal supone una intencionalidad motriz, esto es, un nexo indisociable entre movimiento como tal y consciencia de movimiento. La armonización sistemática de estos dos niveles (perceptivo-motriz) es lo que permite que el cuerpo se haga signo inmediato sin necesidad de percibir primero la formulación mental de un desplazamiento muscular para después atender dicha solicitud con las extremidades requeridas, pues:

(...) El sujeto situado frente a sus tijeras, su aguja y sus faenas familiares no tiene necesidad de buscar sus manos o sus dedos, puesto que no son objetos que hay que buscar en el espacio objetivo, huesos, músculos, nervios, sino potencias ya movilizadas por la percepción de las tijeras o de la aguja, la punta central de los 〈hilos intencionales》 que lo vinculan con los objetos dados. (Merleau-Ponty, 1993, p. 123)

Esta es la razón por la que Merleau-Ponty (1993, pp. 168-169) equipara al cuerpo con la obra de arte, debido a que el cuerpo adapta su percepción y motricidad al direccionamiento de su experiencia con los objetos para así constituir un campo de visión y de acción en el mundo. En este sentido, el cuerpo utiliza su capacidad para captar significaciones asociadas a modos de ver y de moverse y ser él mismo la significación una vez que hace suya cualquier habilidad expresiva. Este proceso, concluye Merleau-Ponty, se designa con el nombre de Habitud: "aptitud para moldear el ser-del-mundo a través del uso de objetos como instrumentos que se anexan a nuestro esquema corpóreo con el ánimo de ampliarlo" (Merleau-Ponty, 1993, p. 161); un claro ejemplo de esto es el bastón del ciego, el cual le permite reconocer el mundo más allá de sus manos, dado que su sentido del tacto se "expande".

No obstante, si bien las especificidades conceptuales que se le atribuyen al cuerpo ha sido detalladas dentro de la filosofía merleau-pontyana, también es 
cierto que todavía se carece de una interpretación sociológica que cimente el análisis de dicha variable y que la enraíce en un cúmulo temático de situaciones sociales concretas. Para consolidar este aspecto recurriremos a López Sáenz (1995), quien realiza una lectura crítica de la fenomenología de Merleau-Ponty cuya finalidad es extraer las consideraciones que el pensador francés propuso acerca de la participación del cuerpo en las relaciones sociales.

En primera instancia, según López Sáenz (1995), Merleau-Ponty parte de una reformulación de la relación Yo-Otro. Frente a este marco problemático, Husserl había postulado la idea de Intersubjetividad como un intercambio entre dos subjetividades que buscan establecer un mundo objetivo por encima de sus intencionalidades individuales. Por su parte, Merleau-Ponty subvierte este concepto, e infiere que la Intersubjetividad es la tensión viviente que experimentan los individuos en sus relaciones de coexistencia social e histórica, es decir, la sociedad no es el resultado de la simple adición de las subjetividades, sino una estructura dialéctica donde el individuo interviene al mismo tiempo en que es intervenido. De esta forma, la cuestión de la intersubjetividad se centra en el mundo vivido, lugar en el que sucede la convergencia Yo-Otro, puesto que ambas subjetividades se encuentran bajo condiciones de existencia comunes.

En este punto, subraya López Sáenz (1995), que el esquema corpóreo adquiere un peso sustancial en el reconocimiento del Otro, debido a que la percepción visual de su cuerpo (esquema corpóreo que él experimenta como suyo) es la demostración fehaciente de que sus acciones o sus conductas tienen su origen en una consciencia similar a la nuestra. Por ende, la consciencia de mi propio cuerpo y la percepción del Otro en tanto reflejo de una existencia externa a la mía, le otorgan a la intersubjetividad de los siguientes rasgos:

a) El cuerpo del Otro es la reproducción fidedigna de las relaciones que comparto con mi propio cuerpo.

b) El cuerpo del Otro mantiene con el Yo una relación de co-percepción respecto al mundo vivido. Esto quiere decir que el cuerpo del Otro no puede ser reducido a un objeto por la consciencia del Yo. 
c) La intersubjetividad es esencialmente intercorporeidad, pues la comprensión del Otro por parte del Yo (y viceversa) sólo puede darse a través de la observación de sus acciones y comportamientos, los cuales se manifiestan en su cuerpo.

Dichos caracteres, sostiene López Sáenz (1995), nos conceden el ítem primordial para el estudio de la intersubjetividad: el comportamiento. Con lo anterior, al asumir a los Otros como consciencias encarnadas que actúan en el mundo según una intencionalidad dada, también puedo llevar a cabo razonamientos comprensivos de las formas en que esos otros intervienen en el mundo y los objetos que comparten conmigo; en último término, el ser-del-mundo, factor inicial del sistema merleau-pontyano, se traspone en una segunda acepción: el estar-en-el-mundo-y-con-los-otros, la cual condensa el plano interactivo que orienta las relaciones y prácticas sociales.

En esta misma corriente, Berger y Luckmann (2008), consideran que es necesario tener en cuenta que las circunstancias culturales e históricas influyen por completo en el desarrollo de la intersubjetividad, ya que la construcción del Yo y del Otro (como esquemas corpóreos con determinadas funciones) se circunscribe a las dinámicas de sus grupos sociales de referencia, los cuales dictaminan las condiciones en que el organismo humano debe reaccionar ante la exigencias de su ambiente natural y sus compromisos colectivos. Por esta razón, el comportamiento está estrechamente ligado a un orden social, el cual amplia o restringe el rango de la acción perceptiva o motriz de los individuos en el mundo vivido, lo que a su vez también posibilita la demarcación de un contexto para la aprehensión del sentido que guardan dichas acciones perceptivas o motrices:

(...) podemos señalar el hecho evidente de que todo desarrollo individual del organismo está precedido por un orden social dado; o sea, que la apertura al mundo, en tanto intrínseca a la construcción biológica del hombre, está siempre precedida por el orden social. (Berger y Luckmann, 2008, p. 70)

Finalmente, para Berger y Luckmann (2008) el punto caliente de la intersubjetividad se sitúa en la Habituación, que consiste en el espectro de actividades significativas que se instauran como pautas de comportamiento 
humano en un grupo social determinado. Ciertamente, esta codificación genérica de los patrones de conducta conlleva a la Institucionalización cuando "se da una tipificación recíproca de acciones habitualizadas por tipos de actores" (p. 74); es decir, las instituciones ejercen un cierre dual en la medida que cumplen la función de asignar una serie de acciones habituales a conjunto de actores determinados, y de regular el comportamiento humano para que responda a esta normatividad establecida.

Por lo tanto, bosquejar una investigación de la memoria colectiva del cuerpo en la literatura entraña un análisis cuidadoso de los recuerdos compartidos asociados a las habituaciones o comportamientos rutinarios que engloban el esquema corpóreo de los personajes; pero, ¿Cómo clasificar el conglomerado de estos recuerdos compartidos sobre habituaciones de los personajes en unas categorías objetivas? Y ¿Cómo compulsar los recuerdos compartidos de las habituaciones de los personajes para hacerlos compatibles o diferenciables dentro de estas categorías? La disposición de estas preguntas no es azarosa, porque el cuerpo es una totalidad que se sustenta en una amplia gama de procesos simultáneos que vale la pena acotar por sus singularidades e incluir en un catálogo especializado, al menos en un nivel tentativo. Además, la prescripción de unos tipos ideales proporcionan un respaldo instrumental cómodo que nos permite distribuir las experiencias corporales de los personajes tanto en su carácter biológico como en su significación social y evaluar el contraste que existe entre los personajes (representantes de un grupo social dado) en cuanto a la valoración ideológica del cuerpo.

De esta manera, el marco metodológico que se propone a continuación para el estudio de la memoria colectiva del cuerpo en la literatura, se corresponde respectivamente, con los caracteres de la intersubjetividad ya expuestos por López Sáenz (1995):

a) Plano de la Percepción: Afecciones y Emociones. Si el cuerpo del Otro es la reproducción fidedigna de las relaciones que comparto con mi propio cuerpo, entonces, los grupos sociales pueden fundamentar sus recuerdos a 
partir de las alteraciones físicas y las secuelas psicológicas que sufre el esquema corpóreo.

b) Plano del Movimiento: Gestualidad. Si el Otro se me da como un objeto inagotable, pero cuya experiencia en el mundo puedo entender a través de su "materialidad" significativa, entonces, los grupos sociales pueden fundamentar sus recuerdos a partir los códigos de comunicación no-verbal en los que media el esquema corpóreo.

c) Plano del Habitud: Instrumentalidad. La intersubjetividad es esencialmente intercorporeidad, pues la comprensión del Otro por parte del Yo (y viceversa) sólo puede darse a través de la observación de sus acciones y comportamientos, los cuales se manifiestan en su cuerpo. Entonces, los grupos sociales pueden fundamentar sus recuerdos a partir los objetos que se integran al esquema corpóreo.

Ahora, por razones de extensión textual y temática, no es posible abordar por completo el método sugerido, por lo que se ha optado por incluir de manera provisional solamente dos variables para el Plano de la Percepción, mientras que los Planos del Movimiento y del Habitud cuentan con una.

\subsection{El Dolor}

De acuerdo con Le Breton (1999), el dolor es ante todo una manifestación situacional, ya que el individuo le confiere un significado que coincide con las circunstancias en las que aparece. En este sentido, el dolor es una experiencia íntima que no rebasa los límites del propio cuerpo, es decir, se incrusta en el organismo haciéndose parte del Yo (que lucha por deshacerse de algo que lo habita por completo), aunque esto no impide que pueda estar mediatizado por factores sociales. Es por ello que la sensación de dolor (sensory pain) siempre se relaciona con una percepción personal (suffering pain), la cual introduce una serie de aspectos problemáticos (en el nivel del sentido y del valor) que ponen en 
entredicho la relación simbólica que tiene el hombre con el mundo (Le Breton 1999, p. 12) ${ }^{7}$.

Frente a esto, si establecemos un punto de contacto entre la conceptualización propuesta por Le Breton (1999) y la filosofía del cuerpo de Merleau-Ponty, vemos que el dolor obstaculiza la índole fundamental del ser-delmundo en tanto instauración de un conjunto de tareas a consumar por parte del sujeto, pues resquebraja la unidad del hombre con su medio contextual, y por consiguiente, la posibilidad de acercarse a los objetos y sus semejantes.

De hecho, el dolor causa una disociación entre la consciencia y el esquema corpóreo, porque, en lugar de normalizar su apertura al mundo, le cierra el paso y obliga al individuo a encerrarse en un cuerpo que no le responde pero que se le impone constantemente (Le Breton, 1999, pp. 24-25). Esto hace que el dolor modifique los comportamientos del individuo, que se lamenta frente a los otros 0 que opta por alejarse para evitar la mirada de los otros. Precisamente, a partir de esta explicitación del dolor, Le Breton (1999) despliega una jerarquización del sufrimiento:

- Dolor Agudo: Es el dolor que siempre nos acompaña, el dolor de todos los días, producto de lesiones y malestares momentáneos. La persona que lo sufre tiende a no preocuparse dado su naturaleza efímera. (p. 28)

- Dolor Crónico: Es el dolor que se interpone entre nosotros y el mundo. Se caracteriza por su intensidad variable, pero más que todo por su insistencia prolongada (p. 31).

- Dolor Total: Es el dolor que se ha apoderado completamente de la persona, pues esta ya no mantiene un lazo con el mundo y sólo sabe que existe porque el dolor le cause un profundo sufrimiento que es próximo a la muerte (p. 35).

\footnotetext{
${ }^{7}$ Desde un punto de vista biológico, Le Breton (pp. 13-14) explica que el dolor es un fenómeno ambiguo pues protege la integridad física a través del reflejo de retracción y la fijación en la memoria de restricciones a acciones negligentes, y al mismo tiempo, es preciso reconocer que el dolor resulta perturbador para el hombre, dada la influencia masiva con la que llena su existencia.
} 
Sin embargo, para Le Breton (1999) es necesario vincular esta escala con una serie de categorías, usuales a todos los grupos sociales, que reflejan los modos en que se vive el cuerpo: 1. Forma: El cuerpo como una totalidad que tiene unos límites precisos en el espacio. 2. Contenido: El cuerpo como un sistema complejo que percibe las sensaciones que proveen significados sobre el mundo circundante. 3. Saber: El cuerpo como un lugar del conocimiento, el cual puede ayudar a entender los procesos que se suscitan en aquél. 4. Valor: El cuerpo como objeto discursivo, por lo que puede ser juzgado de acuerdo a su presentación o sus características. En síntesis, esta intersección entre lo fisiológico y lo cultural hacen del cuerpo una representación que requiere de una comprensión (lectura coherente) de su realidad significativa para obtener una interpretación adecuada del origen del dolor y su simbolismo.

\subsection{El Hambre}

El campo simbólico del hambre es un campo que aún se encuentra en proceso de formación, por lo tanto, sólo haremos alusión a su esencia más allá de sus aristas sociales, económicas y políticas. Así, la depuración crítica del hambre corre por cuenta de la fenomenología de Guínez (2014), el cual lleva a cabo el método husserliano de la variación imaginativa, en el que se plantea una vivencia dada desde diferentes ángulos con la intención de colegir aquellos elementos principales de la vivencia en cuestión que prevalecen a pesar de los cambios efectuados.

De esta manera, Guínez (2014) concluye que el hambre es una experiencia aflictiva que se instaura en el cuerpo, agregando que esta se dirige especialmente al estómago. Esto nos acerca a la designación universal del hambre como una carencia, es decir, una privación que debe llenarse por un objeto en particular ${ }^{8}$. Pero, interroga Guínez: ¿Cuál es ese objeto que elimina el hambre y le da paso a la saciedad? (p. 294). De aquí se desprenden un encadenamiento deductivo:

\footnotetext{
${ }^{8}$ El hambre tiene una cercanía con el dolor en la medida que inducen el mismo estado: el hombre olvida o rompe su relación con el mundo ya que vierte su atención en aquello que lo invade.
} 
a) El hambre no coincide con la desnutrición, pues el segundo estado no es vivido expresamente, sino que proviene de una constatación médica; el hombre puede saciarse sin necesidad de nutrirse.

b) El hambre no coincide con el acto de comer, debido a que la ingesta de "comida" (en su definición esencial) no garantiza la desaparición del hambre.

c) La comida y el hambre sólo se conectan cuando la primera es vista como alimento, pues el alimento es aquél objeto que busca el hambre. De cualquier forma, usa como salvedad Guínez (2014, p. 296), el hambre de ningún modo tiene que ver exclusivamente con llenar el estómago, ya que puede alcanzar niveles simbólicos que ameritan un espacio de reflexión.

\subsection{La Gestualidad}

Este segmento está dedicado a los movimientos significativos que articulan los seres humanos con su esquema corpóreo. El surgimiento de este ámbito de investigación se lo debemos a Birdwhistell (Como se cita en Winkin, 1982, p. 72), quien postuló la existencia de un repertorio motriz de origen cultural encargado de comunicar información en la interacción social al cual denominó sistema kinésico. Con lo anterior, la estructura teórico-metodológica de la Kinesia, como estudio del "comportamiento motor independiente de toda interacción con el lenguaje verbal" (Birdwhistell, 1968, p. 101), se encuentra en la lingüística descriptiva y estructural, las cuales le suministraron una ruta de observación y un índice terminológico. De este modo, la unidad primaria de todo acto motriz-comunicativo es el Kinema (análogo al fonema de la lingüística), que consiste en un movimiento diferenciado (cierre de un párpado para cerrar el ojo) que puede enlazarse a otros Kinemas (en el ejemplo citado, movimientos que acompañan al cierre del ojo como levantar la mejilla $\circ$ el descenso la ceja) para formar Kinemorfemas (análogos a los morfemas) o proposiciones discursivas no-verbales complejas (la suma de los movimientos anteriores forma un "Guiño", señal de complicidad, coqueteo, aprobación, etc., dependiendo del contexto) (Birdwhistell, 1982, p. 169-170). 


\subsection{El Vestido}

De acuerdo con Entwistle (2002), el cuerpo nunca se encuentra desnudo en sociedad, es decir, el mundo vivido es un mundo conformado por cuerpos vestidos. En este sentido, los grupos sociales buscan "vestir" el cuerpo con un haz de opciones culturalmente determinado (tatuajes, perfumes, prendas, cosméticos, etc.) debido a que la visualización del cuerpo en sociedad reclama el uso o la disposición de ciertas "prendas" que sean apropiadas a la situación en que se encuentra (Entwistle, 2002, p. 11).

Además, continúa Entwistle (2002), el vestido juega un papel importantísimo en la interacción social en la medida en que, a través de las prendas que se usan, el esquema corpóreo puede transmitir una imagen, un sentido, o una identidad que es captable por los demás. Esta es la razón por la que la ropa es un instrumento que se integra al esquema corpóreo, pues realiza la presentación del sujeto en su contexto social. Por otro lado, es tal la fuerza con la que se regula el fenómeno de la vestimenta que su contraparte, el desnudo, se halla subordinado a las convenciones o habituaciones de lo que es estar vestido, verbigracia: una mujer de un anuncio publicitario puede no llevar ropa y aun así estar "vestida" por joyas o perfumes (Entwistle, 2002, p. 13). Así, la ropa o la vestimenta en general tienen una connotación moral que se remite al orden social instaurado, ya que aquella es una extensión del cuerpo, es decir, es una parte que debe ser cuidada (desde el punto de vista ético y estético) para su puesta a disposición de la mirada de los otros. No obstante, es lícito recordar que la indumentaria sólo puede significar cuando está unida al cuerpo, porque su propietario y su identidad le permiten ser una totalidad de sentido; esta proposición nos aproxima a una nueva percepción de la vestimenta, que ya no debe ser asumida como un objeto, sino como: "una práctica corporal contextuada" (Entwistle, 2002, p. 16). 


\section{EI Cuerpo en la Literatura}

Una vez que hemos establecido una estructura de apropiación teóricometodológica de los componentes del cuerpo que pueden ser filtrados por la memoria colectiva en la literatura, el siguiente paso es proceder a una aplicación práctica de dicha estructura en unas situaciones determinadas. En todo caso, es necesario hacer la salvedad que estos análisis no son de ningún modo exhaustivos, pues cumplirán más que todo una función ilustrativa, es decir, con ellos se busca trazar un recorrido programático con ciertos nodos de sentido que posibiliten una interpretación adecuada de los textos literarios.

3.1. El dolor como manifestación moral en En la colonia penitenciaria de Franz Kafka

En esta novela corta, Kafka ([1919] 1995) nos entrega un testimonio revelador de las relaciones de poder y de la evolución del sistema penal occidental. Para empezar, este relato se sitúa en un lugar impreciso del que poco se sabe sobre su localización geográfica, ya que la única alusión a dichas coordenadas recae vagamente en la mención del trópico:

-Estos uniformes son demasiado pesados para el trópico -dijo el explorador, en vez de hacer alguna pregunta sobre el aparato, como hubiera deseado el oficial.

-En efecto -dijo éste, y se lavó las manos sucias de aceite y de grasa en un balde que allí había -, pero para nosotros son símbolos de la patria; no queremos olvidarnos de nuestra patria. (p. 7)

Con lo anterior, es importante señalar que la colonia penitenciaria se caracteriza por tener un método particular de castigo que es duramente cuestionado por la administración del nuevo comandante: una máquina que tatúa en el cuerpo del condenado una sentencia relacionada con la ley que quebrantó, la cual produce la muerte del condenado luego de hacerlo pasar por un sufrimiento indescriptible. En efecto, de aquí surgen dos preguntas ¿Qué marcas textuales nos remiten a la dicotomía de Mando/Obediencia? ¿Cómo se transforma el dolor en una manifestación moral y jurídica?

Para responder a la primera pregunta es necesario polarizar ideológicamente a los personajes principales del relato: 1. El Oficial: Tiene al 
mando el funcionamiento de la máquina y es partidario del régimen del anterior comandante de la colonia penitenciaria, el cual es el creador de la máquina. 2. El Condenado: Un soldado que desobedeció a su amo al quedarse dormido mientras estaba de guardia ante su puerta. 3. El Explorador: Observador extranjero que está quedándose por unos días en la colonia penitenciaria para conocer su sistema judicial.

Ahora, si realizamos una observación de la vestimenta de los personajes, se hace explícito un escenario de distinción social. Por un lado, vemos que el oficial porta "chaqueta de gala, ajustada, cargada de charreteras y de adornos" ( $p$. 9); en contraposición, el condenado apenas está vestido, y en un momento dado es desnudado para llevar a cabo la ejecución, pues debe despojarse de su ropa, de una parte de su ser social, para entregarse a la justicia representada en la máquina: “(...) mientras tanto el soldado, ante una señal del oficial, le cortó con un cuchillo la camisa y los pantalones, por la parte de atrás, de modo que estos últimos cayeron al suelo" (p. 27). Esta separación cualitativa de la vestimenta, que podría ser banal, nos remite a una firme consideración: la vestimenta es un símbolo de identidad, pues la ornamentación de la ropa del oficial, su uniforme mismo, es ya una imagen de su pertenencia a un grupo social dominante en la medida que:

(...) la prenda cotidiana siempre es algo más que una concha, es un aspecto íntimo de la experiencia y la presentación de la identidad y está tan estrechamente vinculada con la identidad de estos tres — prenda, cuerpo e identidad-que no se perciben por separado, sino simultáneamente, como una totalidad. (Entwistle, 2002, p. 16)

De hecho, dado que el oficial se asume como una figura de mando, puede llevar a cabo el kinema del señalamiento, usado para acusar a algo o alguien desde una posición de autoridad (Kafka, [1919] 1995):

-Nuestra sentencia no es aparentemente severa. Consiste en escribir sobre el cuerpo del condenado, mediante la Rastra, la disposición que él mismo ha violado.

Por ejemplo, las palabras inscritas sobre el cuerpo de este condenado -y el oficial señaló al individuo- serán: Honra a tus superiores. (pp. 14-15)

Esto nos conduce a la segunda pregunta, debido a que el condenado tiene que padecer el dolor para expiar su violación de la norma jurídica; no obstante, 
antes de desplegar el mapa simbólico de este procedimiento, es preciso describir tanto el funcionamiento de la máquina como la forma en que se estructura el sistema penal de la colonia penitenciaria. En primer lugar, la máquina se compone de tres partes fundamentales (La cama, el diseñador y la rastra), cada una con una función diferenciada:

Sí, la Rastra -dijo el oficial-; un nombre bien adecuado. Las agujas están colocadas en ella como los dientes de una rastra, y el conjunto funciona, además, como una rastra, aunque sólo en un lugar determinado y con mucho más arte. De todos modos, ya lo comprenderá mejor cuando se lo explique. Aquí, sobre la Cama, se coloca al condenado. Primero le describiré el aparato, y después lo pondré en movimiento. Así podrá entenderlo mejor. Además, uno de los engranajes del Diseñador está muy gastado; chirría mucho cuando funciona, y apenas se entiende lo que uno habla; por desgracia, aquí es muy difícil conseguir piezas de repuesto. Bueno, ésta es la Cama, como decíamos. Está totalmente cubierta con una capa de algodón en rama; pronto sabrá usted por qué. Sobre este algodón se coloca al condenado, boca abajo, naturalmente desnudo; aquí hay correas para sujetarle las manos, aquí para los pies, y aquí para el cuello. Aquí en la cabecera de la Cama (donde el individuo, como ya lo dije, es colocado primeramente boca abajo), esta pequeña mordaza de fieltro, que puede ser fácilmente regulada, de modo que entre directamente en la boca del hombre. Tiene la finalidad de impedir que grite o se muerda la lengua. Naturalmente, el hombre no puede alejar la boca del fieltro, porque si no la correa del cuello le quebraría las vértebras. (Kafka, [1919] 1995, pp. 10-11)

En este sentido, la ejecución de la sentencia en la colonia penitenciaria se corresponde con una cuidadosa administración del sufrimiento corporal; es por ello que coincidimos con Damián Repetto (2009), quien efectúa una comparación entre la obra de Kafka y el modo premoderno de castigo denominado suplicio, el cual es categorizado por Michel Foucault (2003) en su obra Vigilar y castigar, y en donde el condenado desconoce el curso de la acusación y el juicio: "La forma secreta y escrita del procedimiento responde al principio de que en materia penal el establecimiento de la verdad era para el soberano y sus jueces un derecho absoluto y un poder exclusivo" (p. 41). Esta circunstancia es visible en la definición del delito cometido por parte del condenado:

-Le explicaré cómo se desarrolla el proceso -dijo el oficial-. Yo he sido designado juez de la colonia penitenciaria. A pesar de mi juventud. Porque yo era el consejero del antiguo comandante en todas la cuestiones penales y, además, conozco el aparato mejor que nadie. Mi principio fundamental es éste: La culpa es siempre indudable. Tal vez otros juzgados no siguen este principio fundamental, pero son multipersonales y, además, dependen de otras cámaras superiores. Éste 
no es nuestro caso o, por lo menos, no lo era en la época de nuestro antiguo comandante. (Kafka, [1919] 1995, pp. 16-17).

Pero ¿Cuáles son las características esenciales del suplicio y de qué modo se articulan con el funcionamiento de la máquina? De acuerdo con Foucault (2003): "El suplicio es una técnica y no debe asimilarse a lo extremado de un furor sin ley." (p. 39), es decir, para que el cumplimiento de una sentencia sea considerado un suplicio, es necesario que se ajuste a tres requisitos básicos que se vinculan con la manipulación consciente del dolor: Cantidad: el sufrimiento debe enmarcarse dentro de una escala convencional de percepción. Grado: el sufrimiento debe remitirse a un método que delimite el orden en que se interviene el cuerpo o sus partes. Duración: el sufrimiento debe dosificarse para extender la vida el mayor tiempo posible. Por ende, en la cuantificación de las magnitudes del dolor:

Existe un código jurídico del dolor; la pena, cuando es supliciante, no cae al azar o de una vez sobre el cuerpo, sino que está calculada de acuerdo con reglas escrupulosas: número de latigazos, emplazamiento del hierro al rojo, duración de la agonía en la hoguera o en la rueda (el tribunal decide si procede estrangular inmediatamente al paciente en vez de dejarlo morir, y al cabo de cuánto tiempo ha de intervenir este gesto de compasión), tipo de mutilación que imponer (mano cortada, labios o lengua taladrados). Todos estos elementos diversos multiplican las penas y se combinan según los tribunales y los delitos: "La poesía de Dante hecha leyes", decía Rossi; un largo saber físico-penal, en todo caso. (ob., Cit. p. 40)

De esta manera, la máquina es una materialización del sistema penal basado en el suplicio, puesto que se adapta a sus tres condicionantes; Cantidad:

La Rastra parece trabajar uniformemente. Al vibrar, rasga con la punta de las agujas la superficie del cuerpo, estremecido a su vez por la Cama. (...) hay dos clases de agujas, dispuestas de diferente modo. Cada aguja larga va acompañada por una más corta. La larga se reduce a escribir, y la corta arroja agua para lavar la sangre y mantener legible la inscripción. (Kafka, [1919] 1995, pp. 20-21)

\section{Grado:}

"La Rastra comienza a escribir; cuando termina el primer borrador de la inscripción en el dorso del individuo, la capa de algodón gira y hace girar el cuerpo lentamente, sobre un costado, para dar más lugar a la Rastra. Al mismo tiempo, las partes ya escritas se apoyan en el algodón, que gracias a su preparación especial contiene la emisión de sangre y prepara la superficie para seguir profundizando la inscripción." (ob., Cit, p. 25) 
Y Duración: "Naturalmente, no puede ser una inscripción simple; su fin no es provocar directamente la muerte, sino después de un lapso de doce horas término medio; se calcula que el momento crítico tiene lugar en la sexta hora." (Kafka, [1919] 1995, p. 24). En todo caso, aún queda por mencionar el aspecto más relevante del suplicio: su carácter ritual, el cual está dirigido a la distinción del condenado a través de la cicatriz y la celebración del triunfo de la justicia en el ámbito público. De hecho, aquí se plantea el contraste que existe entre el antiguo y el nuevo orden que rige la colonia penitenciaria, pues el oficial narra que en tiempos anteriores era común la asistencia multitudinaria a las ejecuciones:

Ya un día antes de la ceremonia, el valle estaba completamente lleno de gente; todos venían sólo para ver; por la mañana temprano aparecía el comandante con sus señoras; las fanfarrias despertaban a todo el campamento; yo presentaba un informe de que todo estaba preparado; todo el estado mayor -ningún alto oficial se atrevía a faltar- se ubicaba en torno de la máquina; este montón de sillas de mimbre es un mísero resto de aquellos tiempos ${ }^{9}$. (...) Y entonces empezaba la ejecución. Ningún ruido discordante afeaba el funcionamiento de la máquina. Muchos ya no miraban; permanecían con los ojos cerrados, en la arena; todos sabían: ahora se hace justicia. (Kafka, [1919] 1995, pp. 33-34)

En últimas, la máquina opera como un objeto perteneciente al plano del habitud, ya que se acopla al esquema corpóreo del condenado para hacer del dolor una exposición de la culpa, la redención de una deuda y la aplicación de una enseñanza, porque la máquina es la instauración efectiva de la justicia, su entrada en el mundo de los objetos. Así, la huella que la ley imprime en el cuerpo, a través del tatuaje, es un símbolo de la anexión del hombre a las normas que se encuentran por encima de él; esta visión es interesante, puesto que la máquina actúa casi como un ser-del-mundo que interviene sobre el verdadero ser-delmundo (el cuerpo humano) para in-vestirlo con su realidad ideal (la sentencia), pues el cuerpo desnudo recibe algo que lo reviste para hacerlo significativo dentro una sociedad determinada. No obstante, el oficial no lleva a cabo la ejecución del

\footnotetext{
${ }^{9}$ Foucault (2003), refiriéndose a la transformación de los sistemas penales a finales del Siglo XVIII e inicios del Siglo XIX, advierte: "Y, sin embargo, tenemos un hecho: en unas cuantas décadas, ha desaparecido el cuerpo supliciado, descuartizado, amputado, marcado simbólicamente en el rostro o en el hombro, expuesto vivo o muerto, ofrecido en espectáculo. Ha desaparecido el cuerpo como blanco mayor de la represión penal" (pp. 15-16). Al mismo tiempo, el deterioro de los objetos asociados al espectáculo punitivo (en particular las sillas de mimbre, correlato del cuerpo relajado que observa con atención) es una metáfora del abandono paulatino de esta práctica social.
} 
condenado debido a que comprende que este método punitivo ya no cuenta con el apoyo de otros oficiales, además, el explorador también tiene pensado pronunciarse en contra de esta práctica:

-Así que el procedimiento no lo convence -dijo éste para sí, y sonrió como un anciano que se ríe de la insensatez de un niño, y a pesar de la sonrisa, prosigue sus propias meditaciones -. Entonces, llegó el momento -dijo por fin, y miró de pronto al explorador con clara mirada, en la que se veía cierto desafío, cierto vago pedido de cooperación.

-¿Cuál momento? -preguntó inquieto el explorador, sin obtener respuesta.

-Eres libre -dijo el oficial al condenado en su idioma; el hombre no quería creerlo-. Vamos, eres libre -repitió el oficial. (Kafka, [1919] 1995, pp. 47-48)

Por tanto, el oficial, consciente del final de una era, decide entregar su cuerpo a la máquina (la sentencia escogida por él es "Se justo") para buscar la justicia que otros condenados encontraron cuando llegaba la sexta hora. En este sentido, repite el mismo ritual en que el condenado es despojado de su ropa, aunque en el oficial adquiere un tono mucho más solemne, porque el hecho de desvestirse con una extraña mezcla de meticulosidad y frustración representa la suspensión definitiva tanto del orden social asociado a esas prendas como de la experiencia corporal de su poseedor: “(...) acarició ligeramente con los dedos los adornos plateados de su chaqueta y colocó una borla en su lugar" (Kafka, [1919] 1995, p. 52) ${ }^{10}$. Del mismo modo, es significativo que la última prenda que se quita el oficial sea el espadín y el cinturón que lo sostiene, pues ambos son símbolos de un poder y un estatus que empieza a declinar: "Sacó el espadín de la vaina, lo rompió, luego reunió todo, los trozos de espada, la vaina y el cinturón, y lo arrojó con tanta violencia que los fragmentos resonaron al caer al fondo" (Kafka, [1919]

10 "Cuando el traje es separado del cuerpo-identidad, como en el caso del museo de la indumentaria, captamos sólo un fragmento, una instantánea parcial del vestido, y por ende nuestra comprensión queda limitada. El museo de la indumentaria convierte el traje en un fetiche, explica cómo se fabricó, las técnicas de costura, los bordados y adornos empleados, así como la etapa histórica en la que fue usado. Lo que no nos puede decir es cómo se llevó ese traje, cómo se movía cuando estaba en un cuerpo, cómo sonaba al moverse y cómo hacía sentir a quien lo llevaba. Sin un cuerpo, un traje carece de plenitud y de movimiento, no está completo." (Entwistle, 2002, p. 16). 
1995, p. 52) ${ }^{11}$. Sin embargo, al encender la máquina, esta no funciona de manera adecuada, por lo que el procedimiento se lleva a cabo incorrectamente en la medida en que el dolor sufrido por el oficial no consta de una estructura lógica, es decir, el suplicio no se apega a las proporciones de cantidad, grado y duración ya descritas en párrafos anteriores:

La Rastra no escribía, sólo pinchaba, y la Cama no hacía girar el cuerpo, sino que lo levantaba temblando hacia las agujas. El explorador quiso hacer algo que pudiera detener el conjunto de la máquina, porque esto no era la tortura que el oficial había buscado, sino una franca matanza. Extendió las manos. En ese momento la Rastra se elevó hacia un costado con el cuerpo atravesado en ella, como solía hacer después de la duodécima hora. La sangre corría por un centenar de heridas, no ya mezclada con agua, porque también los canalículos de agua se habían descompuesto. Y ahora falló también la última función; el cuerpo no se desprendió de las largas agujas; manando sangre, pendía sobre el hoyo de la sepultura, sin caer. (Kafka, [1919] 1995, pp. 57-58)

Por ende, el cuerpo del oficial carece de la marca distintiva (el tatuaje) de aquellos que se entregan a la justicia, por lo que tampoco alcanza la experiencia que redime al condenado: "(...) lo que todos los demás habían hallado en la máquina, el oficial no lo había hallado; tenía los labios apretados, los ojos abiertos, con la misma expresión de siempre (...)" (Kafka, [1919] 1995, pp. 58-59). Al final, el relato termina con la precipitada partida del explorador de la colonia penitenciaria ante el descubrimiento de un culto secreto hacia el antiguo comandante.

3.2. El Hambre como deserción ideológica del mundo en Bartleby, el escribiente de Herman Melville

El personaje de Melville es uno de los personajes más enigmáticos de la historia de la literatura. En este sentido, su actitud apática ante el mundo, su casi palpable indiferencia es una anticipación de Mersault, el personaje de Albert Camus. Pero, ¿Qué hace a Bartleby tan especial? Precisamente su carácter retraído, y su muerte aparentemente injustificada. Frente a esto, habría que decir que el último adjetivo no está por completo en lo cierto, pues su muerte está del

${ }^{11}$ Respecto a la espada rota, Juan Cirlot (1992) sostiene: "Siendo la espada símbolo de la agresividad espiritual, del ánimo del héroe, la espada rota es un símbolo que representa un estado de destrucción de dicho factor." (p. 98). 
todo justificada si atendemos a su esencia fundamental: Bartleby es uno de los primeros personajes representantes de la filosofía nihilista; esto lo podríamos observar si efectuamos un examen de su discurso y comportamiento para comprobarlo.

Partiendo de aquí, Bartleby es un copista de una oficina propiedad de un abogado, en donde inicialmente cumple a cabalidad con su trabajo, pero más tarde empieza a resistirse a realizar cualquier otra función que no tenga que ver con el copiado de documentos. Incluso cuando es solicitado por su jefe, al que siempre responde con la expresión: "Preferiría no hacerlo" (Melville, 1853, p. 6). Ahora, según Gilles Deleuze (2009), el sintagma fijo pronunciado por Bartleby: I would prefer not to (acepción original del "Preferiría no hacerlo") consta de una naturaleza agramatical. En otras palabras, construye una fórmula gramatical poco usual que se ubica en los límites de la validez significativa que ofrece el lenguaje, porque la terminación not to produce un espacio de indeterminación en que el hecho $u$ objeto aludido se mantienen en un estado de ambigüedad frente a la situación en que se hayan enmarcados. Esto ocasiona un panorama en que no existe afirmación o negación, ya que:

Lo desolador de la fórmula consiste en que elimina tan despiadadamente lo preferible como cualquier no-preferencia particular. Anula el término al que afecta, y que rechaza, y que se torna imposible. De hecho, convierte a ambos términos en indistintos: erige una zona de indiscernibilidad, de indeterminación, incesantemente creciente, entre las actividades no preferidas y la actividad preferible. Toda particularidad y toda referencia quedan abolidas. La fórmula anula incluso el ser o no ser preferido. Preferiría nada y no más bien algo: no una voluntad de nada, sino la emergencia de una nada de voluntad. Bartleby se ha ganado el derecho a sobrevivir, esto es, a permanecer quieto y en pie frente a un muro ciego, pura pasividad paciente, como diría Blanchot. Ser en cuanto ser, y nada más. Se le presiona para que diga que sí o no. Pero si dijese que no (que no coteja las copias, que no hace recados...), o si dijese que sí (copia), sería inmediatamente vencido, considerado inútil, y no sobreviviría. No puede sobrevivir más que envolviéndose en esa suspensión que mantiene a todo el mundo a distancia. (p. 7)

En este punto, Deleuze (2009) subraya una noción sumamente valiosa: Bartleby carece de referencialidad, dado que el I would prefer not to efectúa un cierre o una restricción frente a las dinámicas propias de las relaciones y prácticas 
sociales, pues no es posible asignarle un lugar dentro de dicha estructura en la medida en que no se integra y tampoco se contrapone a sus principios internos:

Bartleby es el Solterón, aquel de quien Kafka decía: "No tiene más suelo que el que precisan sus dos pies, ni más punto de apoyo que el que ocupan sus dos manos", el que se tiende en la nieve en pleno invierno para morir de frío como un niño, el que no tiene otra cosa que hacer más que pasear, pero que puede hacerlo en cualquier lugar, sin moverse. Bartleby es el hombre sin preferencias, sin posesiones, sin propiedades, sin cualidades, sin particularidades: demasiado llano como para que se le pueda adherir alguna particularidad. (p. 13)

Precisamente, este carácter en extremo sosegado que posee Bartleby, le permite a Deleuze (2009) establecer unos rasgos tipológicos en torno a los personajes construidos por Melville. Por consiguiente, de acuerdo a estas consideraciones, Bartleby es un personaje hipocondríaco, debido a que se caracteriza por la renuncia a la voluntad, de contextura débil y de apariencia inocente, lo cual lo convierte en una figura que tiende al estatismo propio de un asceta; esto lo hace diametralmente opuesto a Achab, el ballenero de Moby Dick (1851), quien es un personaje monomaníaco, guiado por un sentimiento de fijación, que se obsesiona con aquello que ha elegido hasta confundirse en una voluntad de nada, que persigue por el sólo hecho de perseguir:

Achab perforará el muro aunque no haya nada al otro lado, y hará de la nada el objeto de su voluntad. "Para mí, esa ballena blanca es la muralla que tengo enfrente. A veces pienso que no hay nada al otro lado, pero me da lo mismo". De estos seres, oscuros como los peces que habitan los abismos, dice Melville que sólo un ojo de profeta, y no de sicólogo, puede detectarlos y diagnosticarlos, aunque no pueda prevenirles contra su enloquecida pretensión, "misterio de iniquidad". (p. 21)

Esta conclusión también forma parte de la crítica de Agamben (2009), quien considera que Bartleby es una manifestación de la potencia absoluta, concepto teológico que define la capacidad que tiene Dios para hacer algo, y que se sitúa más allá de la potencia ordinata, que es la conjunción entre ese hacer algo y la voluntad. De esta manera, Bartleby, al pronunciar I would prefer not to (correlato de la potencia absoluta), lleva a cabo una fractura con la ética tradicional, que fundamenta las acciones humanas en el querer y el deber (ramificaciones de la voluntad y la necesidad); esta es la razón, sostiene Agamben (2009), por la que: 
(...) cuando el abogado intenta, a su manera pero con honestidad, comprender al escribiente, las lecturas a las que se dedica no ofrecen duda alguna en cuanto a las categorías de las cuales intenta servirse: Edwards sobre la voluntad, y Priestley sobre la necesidad. Pero la potencia no es la voluntad ni la impotencia la necesidad; pese a la sensación de alivio que le inspiran estas lecturas, tales categorías no consiguen alcanzar la Bartleby. Creer que la voluntad tiene algún poder sobre la potencia, que el paso al acto es el resultado de una decisión que acaba con la ambigüedad de la potencia (que es siempre potencia de hacer y de no hacer), tal es justamente la perpetua ilusión de la moral. (pp. 111-112)

Esto hace de Bartleby un personaje bastante cercano a la doctrina escéptica, puesto que la epoché, en tanto método de suspensión frente a la realidad, se compone a partir del uso de la expresión ou mállon ("no esto más que aquello"), la cual no está dirigida a la afirmación o negación de una circunstancia particular, sino a la experiencia de la posibilidad respecto a esta. Esto quiere decir que Bartleby no es indiferente a la realidad; por el contrario, instaura un escenario con diferentes planos posibles, lo que da lugar a la contingencia, en la que la libertad humana se dilata a partir del ser y no ser (Agamben, 2009, pp. 123-124).

Sin embargo, si bien Deleuze y Agamben nos han proporcionado interpretaciones sólidas del personaje Bartleby, ninguno de estos autores ha centrado su digresión en una observación de las señales que emite el esquema corpóreo de dicho personaje. En su lugar, Byung-Chul Han (2012) si logra realizar un breve diagnóstico psicosomático de Bartleby en función de su pertenencia a una sociedad capitalista que transforma al homo sapiens en homo laborans. En primer lugar, Han (2012) argumenta que el espacio en que se desenvuelven las acciones del relato (la oficina del abogado) produce un efecto patológico sobre los trabajadores que tiene a su servicio, ya que todos desarrollan trastornos asociados a la neurosis: Turkey es hiperactivo, mientras que Nippers padece de irritabilidad; por su parte, el recién llegado Bartleby trae consigo síntomas propios de la neurastenia. Pero, ¿Qué hace del edificio, en tanto espacio social, un lugar tan nocivo? La respuesta se halla en su misma finalidad, la cual se corresponde con el principio de la producción en serie e intensiva, es decir, con un funcionamiento coordinado de los individuos hacia la consecución de un objetivo común, dado que: 
La sociedad que describe Melville es todavía una sociedad disciplinaria. Así, en todo el relato abundan los muros y las paredes, los elementos de una arquitectura propia de dicha sociedad. Pues Bartleby es una «historia de Wall Street». El muro (wall) es una de las palabras más repetidas en el relato. (...) Como representante de la sociedad disciplinaria aparece también, no en último término, el motivo recurrente en Melville- de la prisión y sus muros monumentales, que llama Tombs. Ahí toda vida está extinguida. También Bartleby aterriza en las Tombs y muere en total aislamiento y soledad. Él representa aún un sujeto de obediencia. (Han, 2012, pp. 62-63)

En consecuencia, Han (2012, pp. 64-65) se opone a Agamben, ya que la actitud apática de Bartleby no es una apertura a la posibilidad, sino una reacción causada por el cansancio de una acción repetitiva. De este modo, en Bartleby existe un repliegue paulatino ante aquello que lo consume, esto es, la transcripción de documentos disminuye hasta un punto en que abandona su obligación para ausentarse en sí mismo: "-He renunciado a copiar -contestó y se hizo a un lado" (Melville, 1853, p. 16).

En todo caso, Han tampoco se detiene en el aspecto que consideramos fundamental: el hambre; no obstante, nos ha otorgado la clave que explicita dicha postura: la neurastenia. Por ende, para realizar una aproximación crítica del hambre es necesario definir los rasgos físicos y mentales de ese cansancio y su incidencia en las relaciones y prácticas sociales. En este sentido, una de las primeras características que resalta en Bartleby es la ausencia de emociones, al menos eso sugiere la ausencia de kinemas: "Lo miré con atención. Su rostro estaba tranquilo; sus ojos grises, vagamente serenos. $\mathrm{Ni}$ un rasgo denotaba agitación." (Melville, 1853, p. 6). De hecho, la poca necesidad de comunicarse es un común denominador en Bartleby:

Entonces recordé todos los tranquilos misterios que había notado en el hombre. Recordé que sólo hablaba para contestar; que aunque a intervalos tenía tiempo de sobra, nunca lo había visto leer -no, ni siquiera un diario-; que por largo rato se quedaba mirando, por su pálida ventana detrás del biombo, al ciego muro de ladrillos (...). ( Melville, 1853, p. 13)

Esta forma de presentarse ante el mundo alcanza su cumbre cuando se rehúsa a hablar cuando el abogado lo visita en la cárcel:

¡Bartleby!

-Lo conozco -dijo sin darse vuelta- y no tengo nada que decirle. 
-Yo no soy el que le trajo aquí, Bartleby -dije profundamente dolido por su sospecha-. Para usted, este lugar no debe ser tan vil. Nada reprochable lo ha traído aquí. Vea, no es un lugar tan triste, como podría suponerse. Mire, ahí está el cielo, y aquí el césped.

-Sé dónde estoy -replicó, pero no quiso decir nada más, y entonces lo dejé. (Melville, 1853, p. 24)

Por otro lado, la ropa de Bartleby no está cuidada, es vieja, por lo que es evidente que no ostenta poder o estatus (recordemos el uniforme del oficial de En la colonia penitenciaria); más bien intenta cubrir las necesidades básicas: "Llamé; consternado, vi girar una llave por dentro y, exhibiendo su pálido rostro por la puerta entreabierta, entreví a Bartleby en mangas de camisa, y en un raro y andrajoso deshabillé". (Melville, 1853, p. 11). Además, Bartleby también sufre de un leve trastorno alucinatorio en el que su mente divaga y que se relaciona con un estado contemplativo, el cual se "activa" cuando observa el muro exterior que se ubica en frente de su ventana; este tipo de episodios serán el detonante de su aislamiento definitivo:

Al día siguiente noté que Bartleby no hacía más que mirar por la ventana, en su sueño frente a la pared. Cuando le pregunté por qué no escribía, me dijo que había resuelto no escribir más.

-¿Por qué no? ¿Qué se propone? -exclamé-. ¿No escribir más?

-Nunca más.

- ¿Y por qué razón?

-¿No la ve usted mismo? -replicó con indiferencia. (ob., Cit., p. 15).

En último término, el rasgo simbólico más elocuente en Bartleby, el hambre, es un dispositivo que aglomera toda la totalidad de sentido propia del ser-delmundo recluido evaluado por Deleuze, Agamben y Han. En el final de su vida, Bartleby se encuentra en una cárcel y se niega a comer; este comportamiento es una manifestación de una actitud negativa, una consciencia que se opone a tomar el alimento como un objeto indispensable por su valor significativo. Es por ello que su rechazo al consumo de los alimentos es un cierre que efectúa a propósito su ser-del-mundo, para hacer que se ocupe aún más de sí mismo que de aquello que 
lo rodea. Su muerte, es el escape del esquema corpóreo, de la restricción que representaba el continuo estar-ahí en el mundo.

\section{Conclusiones}

El abordaje de la definición de la corporalidad ha devenido en una estructura teórico-metodológica que, aunque superficial, nos presenta un acercamiento a las principales variables que afectan nuestra estadía en nuestro cuerpo. De esta manera, hace falta redoblar los esfuerzos para tratar de incorporar y hacer confluir las diferentes ramas investigativas que se han ocupado recientemente del cuerpo, además, es necesario retomar la fenomenología merleau-pontyana como un punto de apoyo importante para el desarrollo de nuestras perspectivas del cuerpo. En todo caso, podríamos resumir nuestra breve e inacabada investigación en los siguientes puntos:

a) Los fenómenos pertenecientes al plano de la percepción se caracterizan por nublar el ser-del-mundo del sujeto, es decir, se interponen entre este y el mundo que lo rodea, impidiendo un acercamiento de este a aquellos proyectos o tareas que consideran una necesidad vital por cumplir.

b) Hace falta una estructuración de una fenomenología del cuerpo femenino, pues las obras literarias analizadas están centradas en experiencias vinculadas a sujetos masculinos. Una explicitación más a fondo de este componente nos permitiría una aproximación a la experiencia corpórea de la mujer en tanto sujeto con una forma particular de vivir el mundo. Por ahora sólo postularemos el nombre de la escritora francesa Hélène Cixous.

c) Debido a su carácter demasiado reservado, no fue posible extraer del todo la conceptualización del hambre en Bartleby y sus conexiones con el esquema corpóreo. Por lo tanto, es vital la continuación del estudio de esta obra literaria partiendo de su contrastación con otros textos que tengan por tema central el hambre, tales como el cuento Un artista del hambre de Franz Kafka y la novela Hambre de Knut Hamsun.

d) Es necesario postular nuevos espacios dentro de los planos corpóreos ya descritos en esta investigación, verbigracia, la definición de la enfermedad y 
su relación con la memoria colectiva en la literatura. Podríamos tomar La Peste de Albert Camus como un tentativo objeto de estudio.

\section{Referencias Bibliográficas}

Agamben, Giorgio. Bartleby o de la contingencia. En Preferiría no hacerlo. Ensayos sobre Bartleby. Valencia: Editorial Pre-textos. Recuperado de https://es.scribd.com/doc/138666700/Agamben-Bartleby-o-de-La-Contingencia

Bajtín, M. (1989). Teoría y estética de la novela. Madrid: Altea, Taurus, Alfaguara S. A.

Barreto, R. (2015). Tiempo artístico y Memoria Colectiva: La Casa Grande y Álvaro Cepeda Samudio (Trabajo de grado inédito). Universidad del Atlántico, Barranquilla, Colombia.

Berger, P. \& Luckmann, T. (2008). La construcción social de la realidad. Buenos Aires: Amorrortu Editores.

Birdwhistell, R. (1982). Un ejercicio de kinésica y de lingüística: la escena del cigarrillo. En La nueva comunicación. Volumen I. (pp. 166-197) España: Editorial Kairós.

Cirlot, J. (1992). Diccionario de símbolos. España: Editorial Labor.

Cros, E. (1992) Ideosemas y Morfogénesis del texto. Literatura española e hispanoamericana. Frankfurt am Main: Vervuert.

Cros. E. (2003). El sujeto cultural: Sociocrítica y Psicoanálisis. Medellín: Fondo Editorial Universidad EAFIT.

Deleuze, G. (2009). Bartleby o la fórmula. En Preferiría no hacerlo. Ensayos sobre Bartleby. Valencia: Editorial Pre-textos. Recuperado de https://primeraparadoja.wordpress.com/publicaciones/gilles-deleuze-bartleby-o-laformula/\#sdfootnote14sym

Duchet, C. (1971). Pour une socio-critique ou variations sur un íncipit. Literatura, 1, 5-14. Recuperado de http://www.persee.fr/web/revues/home/prescript/article/litt 004748001971 num 112495 
Entwistle, J. (2002). El cuerpo y la moda. Una visión sociológica. Barcelona: Editorial Paidós.

Foucault, Michel. (2003). Vigilar y castigar. Nacimiento de la prisión. Argentina: Siglo XXI Editores.

Genette, G. (1989). Figuras III. Barcelona: Editorial Lumen S. A.

Goldmann, L. (1975). Para una sociología de la novela. Madrid: Editorial Ayuso.

Guínez, P. (2014). Comida, hambre y fenomenología: En torno a la posibilidad de una fenomenología de la comida. Eikasia, 60, 289-298.

Halbwachs, M. (2004). La Memoria colectiva. Zaragoza: Prensas Universitarias de Zaragoza.

Han, B. (2012). La sociedad del cansancio. Barcelona: Herder Editorial.

Kafka, F. ([1919], 1995). En la colonia penitenciaria. Madrid: Alianza Editorial S. A.

Le Breton, D. (1999). Antropología del dolor. España: Editorial Seix Barral.

López, M. La fenomenología existencial de M. Merleau-Ponty y la sociología. Papers, 50, 209-231. Recuperado de http://papers.uab.cat/article/view/v50lopez/pdf-es

Melville, H. (1853). Bartleby, el escribiente. Una historia de Wall Street. Recuperado de

http://www.edu.mec.gub.uy/biblioteca digital/libros/M/Melville,\%20Herman\%20\%20Bartleby\%20el\%20escribiente.pdf

Merleau-Ponty, M. (1993). Fenomenología de la percepción. Barcelona: Editorial Planeta-De Agostini.

Repetto, D. (16 de Mayo de 2009). El cuerpo de los condenados. Una lectura de En la colonia penitenciaria de Kafka. [Mensaje en un blog]. Recuperado de http://derecho-a-replica.blogspot.com/2009/05/el-cuerpo-de-los-condenados-una-

\section{lectura.html}

Ricoeur, P. (2004). Tiempo y Narración I. Configuración del tiempo en el relato histórico. México: Siglo XXI Editores.

Winkin, Y. (1982). La nueva comunicación. Volumen I. España: Editorial Kairós. 